\title{
VAPORIZATION OF THE UTERUS.
}

\author{
By G. F. BLACKER, M.D., B.S., F.R.C.S.,
} Obstetric Physician to Out-patients, University College Hospital; Obstetric Physician, Great Northern Central Hospital.

THE modern revival of vaporization of the uterus we owe to Professor Sneguireff of Moscow, who in the year 1894 published a paper upon 'The Use of Steam as a Means of Arresting Hæmorrhage.' At that time he had employed it for some six or seven years in his surgical practice, and he had tested its capabilities as a hæmostatic in operations upon the liver, spleen, lungs, kidneys, and other organs. $\mathrm{He}$ found, in an experience of from 400 to 500 cases, that it acted promptly and efficiently in the arrest of hæmorrhage, that it produced no bad after-effects, and that raw surfaces exposed to its action during surgical operations healed by first intention.

While the merit of having introduced this therapeutic measure into gynæcology is due to Sneguireff, we are greatly indebted to Ludwig Pincus of Danzig for the energy with which he has advocated vaporization of the uterus. He has introduced many important modifications into the apparatus employed, has laid down very fully the indications and contra-indications for and against the operation, and has done more than anyone else to establish it upon a firm and scientific basis. While we may not agree with all that Pincus has written upon the subject, we cannot but admire the zeal with which he has endeavoured to enlarge the scope of the operation, and to overthrow the many objections raised to its employment.

The apparatus used consists essentially of a small steam boiler made sufficiently strong to withstand a pressure of three atmospheres, fitted with a safety valve, dynamometer and thermometer, and an exit tube for the steam. The modified apparatus of Sneguireff, which I have used, is fitted with a dynamometer, and is heated by a Bunsen's burner. That recommended by Pincus is fitted with a thermometer, and is heated by one or more spirit lamps. The steam is conducted to the intra-uterine cannula by a thick-walled rubber tube of about I metre in length. The cannula is a modification of the ordinary Bozemann's double-channelled intra-uterine tube, and has, as the tube itself becomes too hot to hold, a protected handle attached to it at right angles. In the model employed by Pincus the outer channel of the cannula is fitted with an outlet tube, so that the returning steam can be led away and does not escape from the 
uterus into the vagina. His apparatus is further provided with a double way stopcock between the steam-tube and the cannula, so made that the steam from the tube may be admitted directly into the cannula or allowed to escape externally. Pincus aims at conducting the steam into and from the uterus by the double-channelled cannula, so as not to allow it to come in contact with the vagina or vulva, while in Sneguireff's pattern of vaporizator the steam escapes directly from the uterus into the vagina, and scalding of the latter passage

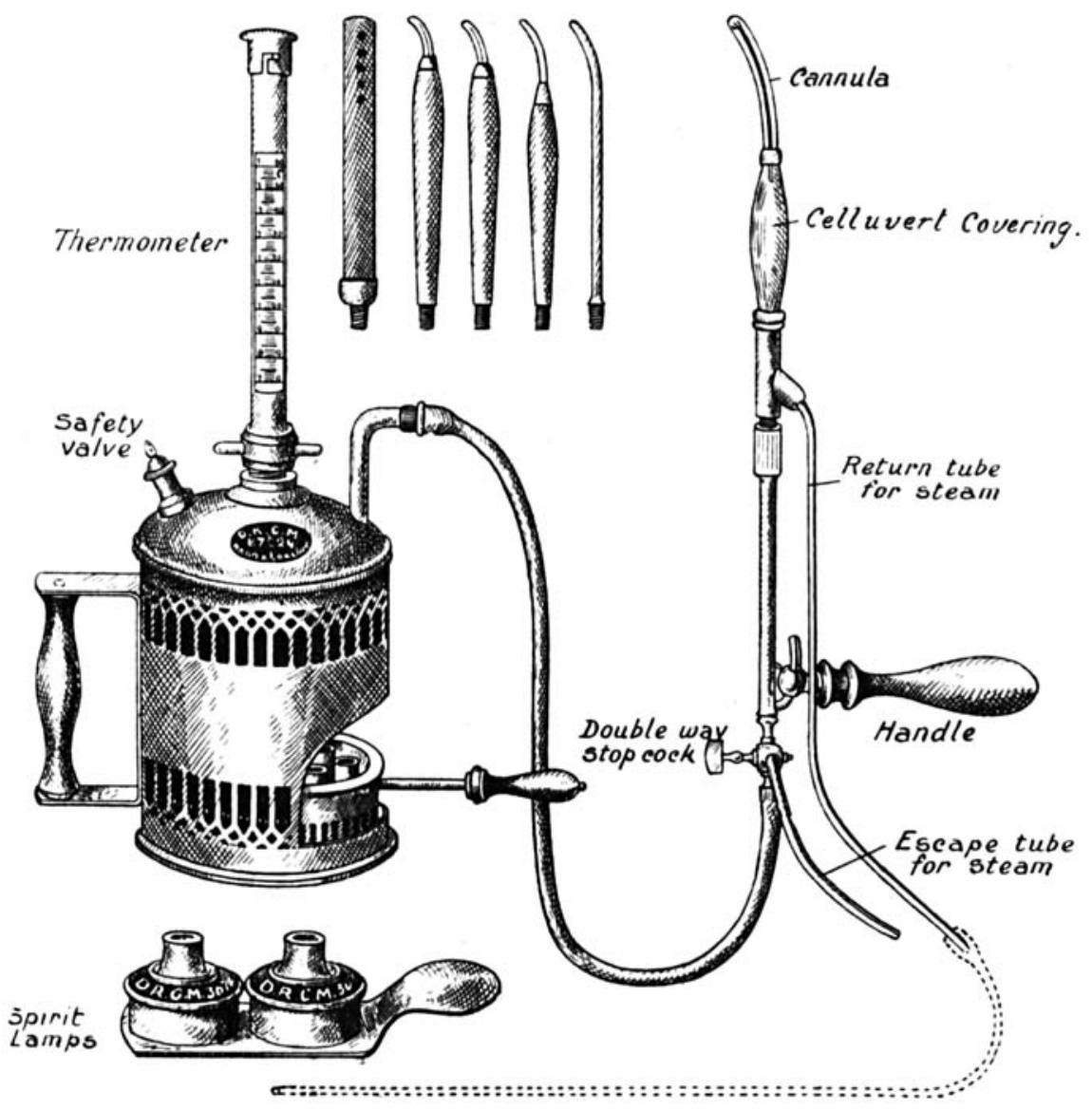

Fig. 1.-Apparatus of Ludwig Pincus.

must be prevented by the employment of a cold douche or some other means.

Pincus has extended and amplified the original recommendations of Sneguireff, and employs the steam in two different ways. In the first, which he calls atmocausis, the apparatus being termed an atmocautery, the steam is allowed to act directly upon the interior of the uterus, while in the second one, which he terms zestocausis, it 


\section{Journal of Obstetrics and Gynæcology}

is employed to heat a hollow intra-uterine metal tube termed a zestocautery, which thus forms a kind of modified cautery. That part of the metal tube which lies in the cervical canal is provided with a protective covering either of celluvert (compressed wood fibre) or of a piece of indiarubber drainage-tubing. If celluvert be employed, it is necessary to have several different tubes corresponding to the varying sizes of the uterine cavities operated upon, while if rubber tubing is used it can be cut to any required length at the time of the operation. The apparatus devised by Pincus is more convenient to use than that of Sneguireff, gives more certain results, and entails less danger of scalding either the patient or the operator.

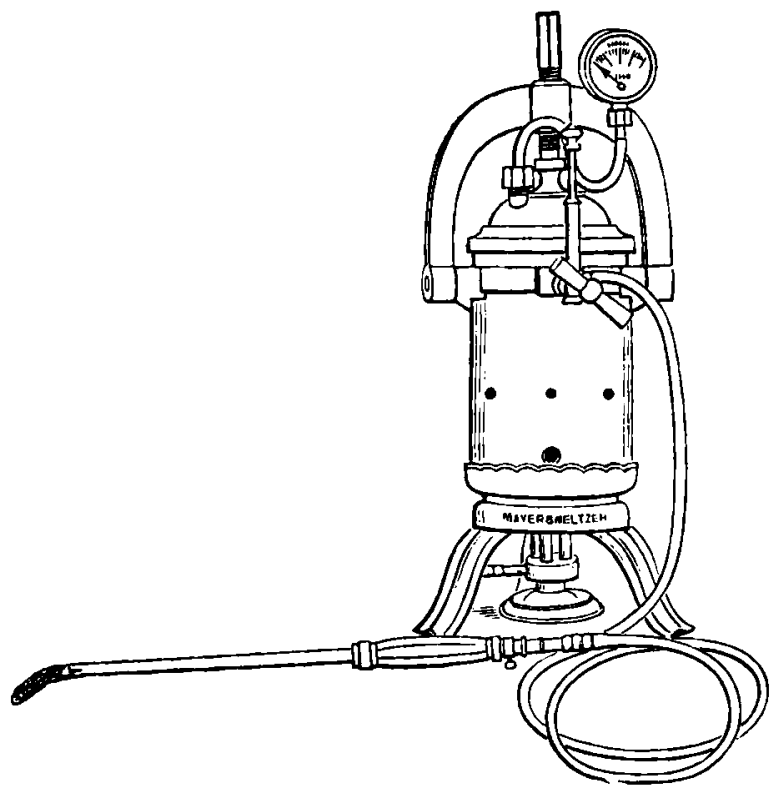

Fig. 2.-Apparatus of SNEguirefF.

Zestocausis has never been practised to the same extent as atmocausis, and the zestocautery does not appear to possess any advantages over the use of either the electric or Paquelin's cautery.

The operation of vaporization of the uterus can be performed without an anæsthetic. There is little or no pain connected with it, and one of the advantages claimed for it is that it can be practised without the production of anæsthesia. The administration of an anæsthetic is, however, preferable in the great majority of cases; not only does it allow the operation to be more efficiently performed, but it has the great advantage of allowing a careful bimanual examination of the pelvis to be made, and so the possibility of overlooking any signs of old or recent pelvic inflammation to be reduced 
to a minimum. It is claimed that the non-administration of an anrsthetic allows the operation to be performed upon out-patients, and that it is an advantage for the patient to be able to say when she feels pain. The pain is probably due to painful contractions of the uterus, set up by the steam commencing to act upon the muscular fibre of the uterine wall after destruction of the mucous membrane. The occurrence of such pain is, then, an indication for ceasing the vaporization; and if the patient is under an anæsthetic this guide is lost. On the whole, however, the advantages that attend the condition of complete anæsthesia of the patient, and the lessened liability there is to the occurrence of scalding from a sudden movement upon her part, renders the administration of an anæsthetic desirable in all cases. The operation should not be performed upon out-patients, and confinement to bed for some days is an essential feature of the after-treatment. The introduction of a laminaria or tupelo tent into the cervical canal over-night is a decided gain. It enables the dilatation of the cervix to be readily carried out with Hegar's dilators to an extent sufficient to admit the finger, and also diminishes the chances of cauterization of the cervical canal during the introduction of the cannula or by the escaping steam. Curettage of the cavity of the uterus may or may not be required. In cases where there is definite thickening of the mucous membrane of the uterus-as, for example, in cases of hypertrophic endometritis-the whole of the interior of the uterus should be carefully curetted before it is steamed. In cases, however, where, on digital examination, little or nothing is found in utero, as often occurs in cases of preclimacteric or climacteric hæmorrhages, preliminary curettage may be omitted. In all cases where the curette is employed the fragments removed should be subjected to a careful microscopic examination, so as to avoid the danger of overlooking a case of early malignant disease.

The operation itself is carried out as follows: With the patient under an anæsthetic, a careful bimanual examination is made. The uterus is then drawn down with a vulsellum, and the cervix dilated with Hegar's dilators sufficiently to admit the finger. The interior of the uterus is explored, and, if necessary, curetted. It is then washed out with an intra-uterine douche of some antiseptic solution at a temperature of $I 15^{\circ} \mathrm{F}$., to arrest the hæmorrhage. If this has not already been done during the progress of the dilatation, the length of the uterine cavity is carefully measured, and a cannula of the right size is selected, or a covering of drainage-tubing cut to a proper length, so that the cervical canal is completely protected. The 


\section{Journal of Obstetrics and Gynæcology}

whole apparatus should be warmed by allowing the steam to pass through it for a few minutes, and while this is taking place, the cannula must be held below the level of the boiler, so that the condensed water which collects in the tubing may readily escape. The posterior vaginal wall and the perineum are protected by a Sims' or wooden speculum. The tube is now introduced into the uterus with the steam shut off, and, by turning the double way stopcock, the steam is allowed to enter for a definite length of time, depending upon the nature of the case and the result desired. The time varies from ten seconds to as long as three minutes. Pincus lays great stress upon using steam at a temperature of at least $115^{\circ}$ to $I 16^{\circ} \mathrm{C}$., and allowing it to act for as short a time as possible-about fifteen to thirty seconds. The time should be measured from the moment at which steam is first seen to escape either from the return tube or from the uterus. During the progress of the vaporization, the cannula may be carefully moved from side to side in the uterus, so as to try and expose the whole surface of the mucous membrane to the action of the steam. After the completion of the operation, a small iodoform gauze packing is placed in the cervix, and another in the vagina. The latter should be removed at the end of from twentyfour to thirty-six hours, and the former after three or four days. If pain in the abdomen is complained of, it can be treated by an icebag or by hot fomentations; it is, however, unusual for any severe pain to be felt.

No special after-treatment is required. Vaginal douches may be given when the sloughs begin to separate about the end of the first week, if it be thought desirable. A thinnish blood-stained discharge usually sets in on the second or third day, and continues for some nine or ten days. The patient should be kept in bed for a week to ten days after the operation. If there are any signs of pelvic inflam. mation, complete rest in bed is essential until they have disappeared. Colicky uterine contractions sometimes occur when the sloughs are being expelled; if severe, they can usually be relieved by passing a speculum and removing with forceps the small shreds of tissue which may be found in the cervical canal or the body of the uterus. If it is necessary to repeat the operation, an interval of three or four weeks must be allowed to elapse.

If a form of apparatus be employed in which the steam and condensed water are allowed to flow back into the vagina, steps must be taken to prevent scalding of the patient. This is best avoided by the administration of a cold vaginal douche during the time that the steam is allowed to pass into the uterus. It can easily be arranged 
so that while the posterior vaginal wall and perineum are bathed by the cold lotion no risk is run of cooling either the uterine cannula or the steam tube, and so causing condensation of the steam.

It is unsafe to attempt to carry out this mode of treatment except with a properly-fitted apparatus. From a neglect of this precaution I have seen scalding occur not only of the patient, but also of the operator and his assistant.

The question as to what is the temperature at which the steam acts in utero is one that has aroused a good deal of discussion. Flatau experimented with uteri removed in the dead-house. These he placed in a hot-water bath until they were raised to a temperature of $38^{\circ} \mathrm{C}$. He then introduced a thermometer into the interior of the uterus through an opening in the fundus, and passed in steam at a temperature of $100^{\circ} \mathrm{C}$. At the end of one minute the thermometer in utero had risen to $65^{\circ}$ to $75^{\circ} \mathrm{C}$., at the end of two minutes to $75^{\circ}$ to $85^{\circ} \mathrm{C}$., and at the end of five minutes to $95^{\circ} \mathrm{C}$. Fuchs points out that Flatau's experiments are not very reliable, because they were conducted with an old-fashioned apparatus in which marked cooling of the steam can occur during its passage to the uterus. Stapler attempted to determine the temperature of the steam by introducing the atmocautery and zestocautery into water at a temperature of $37^{\circ}$ in a test-tube in which a maximum and minimum thermometer was placed. The highest temperature reached with the atmocautery after the lapse of one minute was $90^{\circ}$ to $95^{\circ} \mathrm{C}$., and with the zestocautery, after the same lapse of time, was $90^{\circ} \mathrm{C}$. The water in the boiler stood during the experiments at a temperature of $100^{\circ}$ to $102^{\circ} \mathrm{C}$. Pincus experimented with the uterus of the cow, into one horn of which he tied a thermometer. On passing in steam at a temperature of $\mathrm{I} 15^{\circ} \mathrm{C}$., he found the temperature in the uterus rose to $98^{\circ}$ to $99^{\circ} \mathrm{C}$. in as short a time as 5 to 15 seconds. The value of all such experiments must largely depend upon the relation that the thermometer bears to the inflowing steam. Fuchs employed a Champetier de Ribes' bag to represent the uterus, which he raised to a temperature of $38^{\circ} \mathrm{C}$. by immersion in a water-bath. With the water in the boiler standing at a temperature of $I 18^{\circ}$ to $I I 9^{\circ} \mathrm{C}$. he found, on allowing the steam to flow in, that the thermometer in the interior of the bag reached $98.5^{\circ} \mathrm{C}$. in thirty seconds, and $100.25^{\circ} \mathrm{C}$. in sixty seconds. The loss of heat during the passage of the steam from the boiler to the tube amounted, therefore, to about $20^{\circ} \mathrm{C}$. It must be borne in mind that the conditions when the steam is under a pressure of two or three atmospheres in the boiler are quite different from those which obtain 


\section{Journal of Obstetrics and Gynæcology}

when it is allowed to flow more or less freely through the steam-pipe and the cannula. A fall of pressure must at once occur in the latter case, which is, of course, accompanied by a corresponding fall of temperature. It is impossible to raise steam to a temperature of more than $100^{\circ} \mathrm{C}$. except under pressure. Pincus does not believe that the loss of heat amounts to more than about $8^{\circ} \mathrm{C}$., and maintains that the fall of pressure can be to some extent obviated by not allowing the steam to escape freely through the return-tube of his apparatus. The pressure in the uterus cannot, even under these conditions, much exceed that of the atmosphere, and it is therefore hardly possible for the steam in utero to be at a higher temperature than $100^{\circ} \mathrm{C}$., even if it always reaches that point, which seems improbable. If it does, it certainly cannot be maintained at such a high level for more than a very short time.

Koslenko, experimenting with the uteri of dogs, found that the higher the initial temperature the more rapidly the loss of heat occurred. Under a pressure of two atmospheres he obtained a temperature of $\operatorname{II} 5^{\circ}$ to $I 16^{\circ} \mathrm{C}$. in utero, which lasted for only five to ten seconds. A temperature of $100^{\circ} \mathrm{C}$. could be maintained for five minutes, a temperature of $106^{\circ}$ to $108^{\circ} \mathrm{C}$. for half a minute, and a temperature of $I I 0^{\circ}$ to $I I I^{\circ} \mathrm{C}$. for a quarter of a minute. The results of these various experiments are somewhat contradictory, but we shall probably be correct in saying that the temperature of the steam in the uterus rarely reaches $100^{\circ} \mathrm{C}$., and never exceeds that point. The contention of Flatau that the results obtained depend rather upon the action of hot water than upon that of steam is probably well founded, and must be admitted as correct in, at any rate, many instances. It is also impossible to deny that probably the heat of the catheter itself plays an important part in causing the effects observed.

Passing on to consider the actual results produced upon the uterine mucous membrane, we again find very divergent statements.

That the steam is capable of producing necrosis of the whole of the mucous membrane and complete obliteration of the cavity of the uterus is certain from the cases recorded by Dührssen and others. The reasons are not at all clear why in one case an application of steam at a temperature of $100^{\circ}$ to $105^{\circ} \mathrm{C}$. for only half a minute will produce such a result, while in another case the application of steam at a temperature of II $5^{\circ}$ to $120^{\circ} \mathrm{C}$. for as long as two minutes produces only superficial destruction of the mucous membrane of the uterus. The difference appears to depend upon the size and shape of the uterine cavity, the degree of the uterine contraction that is 
produced by the entrance of the steam-the more marked the uterine contraction the greater, as a rule, the effect-and the amount of blood or discharge that is present in utero at the time. It is not uncommon to find the effects produced much more marked at some points than at others, and it is probable that when this is so the action has been due to the heat of the hot tube-viz.; to zestocausis-and not to the action of the steam or atmocausis.

The danger of such a cauterization of the uterine wall is well illustrated by Treub's case, reported by Van de Velde, of death following perforation of the uterus. To avoid this danger the intrauterine tube should not be introduced for more than two-thirds of the distance from the internal os to the fundus, and the point of the instrument should not be allowed to press upon the inner surface of the uterine walls during the operation. For this reason those forms of cannulæ in which the flow of steam is directed backward are not very suitable, since if the rule be observed not to pass the cannula up to the fundus of the uterus, with the use of such an instrument a considerable portion of the uterine wall will not be exposed to the action of the steam. The irregular distribution of the effects upon the mucous membrane gives some colour to the contention that they are produced by the action of hot water rather than by that of steam. It was at first thought that one of the great advantages of this mode of treatment would lie in the uniform effect produced upon the whole of the surface of the uterus to which the steam had had access, and for this reason good results were anticipated in cases where the uterine cavity was irregular from the presence of fibroid tumours. No such general effect is, however, produced, and the best results are obtained in uteri with a small and regular cavity.

Koslenko has examined uteri removed on the first to the ninth day after vaporization had been carried out for twenty seconds with steam under a pressure of two atmospheres, at a temperature, therefore, of about $115^{\circ}$ to $120^{\circ} \mathrm{C}$. Microscopic sections showed destruction of the superficial layers of the mucous membrane and a small-celled infiltration of the tissues in the neighbourhood. Portions of the mucous membrane retained their surface epithelium intact, and only the superficial part of the glands had been destroyed, nothing like total destruction of the mucous membrane being found. In the cervical canal the epithelium on the summits of the ridges of the arbor vitæ had been destroyed, but not that in the intervening depressions. From an examination of his specimens he concluded that the separation of the necrosed tissues occurred from the third to 


\section{Journal of Obstetrics and Gynæcology}

the sixth day, when they were usually expelled, and that regeneration of the mucous membrane began about the ninth day.

Czempin, in a uterus removed from a patient two months after vaporization for two minutes had been practised, found that in the places where the mucous membrane had been shed a new but atrophied membrane had developed. It consisted of a thin layer of connective tissue showing a small-celled infiltration with some large capillary vessels, with no signs of any glands, and covered by a single layer of epithelium. He thought such a condition would be found present in those cases where the periods failed to reappear after the performance of vaporization, but where the uterine cavity remained patent. In a uterus removed on the tenth day after steaming for fifteen seconds at a temperature of $112^{\circ} \mathrm{C}$., Falk found the following condition: Dark red sloughs were present upon the lateral walls of the uterus, œdematous swellings at the tubal angles, and unaltered epithelium at the fundus and between the necrotic patches. Microscopic examination showed unaltered mucous membrane in the immediate neighbourhood of sloughs which extended down to the muscular coat. The elastic and muscular fibres showed signs of chronic metritis, but had not been affected by the steaming.

Pit'ha, by introducing the cannula first into one angle of the uterus and then into the other, produced an effect upon almost the whole of the mucous membrane. He found the sloughs partly separated on the tenth day, and completely so on the fourteenth day after vaporization.

Prochownick examined six uteri extirpated after vaporization. In those steamed with the apparatus of Pincus he found very irregular and unequal changes in the mucous lining. In the cases treated with Dührssen's model the results were more regularly distributed, and consisted of destruction of the epithelium, and of the sub-epithelial layer, and retention of the deeper parts of the glands. The discharge of complete casts of the mucous membrane of the uterus down to and even including the superficial part of the muscular coat shows that such total destruction can occur. We are, however, at present unable to say definitely in what class of cases it is likely to occur, or in what kind of uterus it can be obtained with certainty, if desired. In four cases recorded by Dührssen total obliteration of the uterine cavity took place in three, while in the remaining one the uterus underwent definite atrophy. In all four permanent cessation of the menses followed the operation. An examination of these results shows that at times the destruction of the mucous membrane produced is very complete, and the chief 
danger of the operation in young women is the difficulty of certainly controlling the effect produced. The observations of other observers do not bear out the contention of Pincus, who maintains that it is casy to graduate the effects produced upon the mucous membrane by varying the temperature of the steam or the length of time for which it is applied.

The chief dangers and complications that may attend the operations of atmocausis and zestocausis are as follows:

I. Inflammation of the pelvic peritoneum, the cellular tissue, the ovary or the tube.

2. Stenosis and atresia of the cervix.

3. Complete necrosis of the mucous membrane of the uterus and obliteration of its cavity.

4. Excessive atrophy of the uterus.

5. Perforation of the uterine wall.

In order to reduce the danger of setting up inflammatory conditions in the pelvis, the rule must be adhered to that the presence of any signs of old or recent pelvic inflammation are an absolute bar to the practice of vaporization. Indeed, this forms its main contraindication. Out of $\mathbf{I}_{45}$ cases recorded by Schäffer, Steinbüchel, Flatau, and Schlutius, in 8 or $5^{\circ} 5$ per cent. of the cases pelvic inflammation occurred. In two cases a mild attack of pelvic cellulitis occurred, in two cases an attack of pelvic peritonitis, and in four cases an acute exacerbation of pre-existing inflammatory conditions. In one of the cases in which parametritis set in the zestocautery had been used, and in the remaining cases the atmocautery.

V. Guerard has recorded a case of total extirpation of the uterus on account of severe pains following the operation of atmocausis. The patient, thirty-one years of age, had borne three children. After ventrofixation had been performed upon her for chronic abdominal pain, she became pregnant, and miscarried at the fifth month; severe hæmorrhage occurred during the puerperium, persisting for some considerable time, and for this atmocausis was performed. No details are given either of the temperature of the steam or of the length of time for which it was applied. The patient was confined to bed for five or six weeks after the operation, and for the first six or seven days complained of pelvic pain. The periods failed to reappear, but very severe attacks of abdominal pain occurred at fairly regular intervals. On examination, the uterus was found to be anteflexed and fixed, there were inflammatory masses in both posterior quarters of the pelvis, and the sound could not be passed into the uterus. Total extirpation of the uterus, which measured 


\section{Journal of Obstetrics and Gynæcology}

I centimetres in length, was carried out, and its cavity was found to have entirely disappeared. The author suggests that the failure of the uterus to atrophy after obliteration of its cavity was the cause of the pains, but the chronic inflammation of the appendages and the previous ventrofixation may have been contributory factors.

Van de Velde's fatal case was that of a woman who had suffered from severe hæmorrhage for fourteen weeks. The uterus and appendages appeared normal. After dilatation of the cervix up to a size corresponding to No. 1o of Hegar's dilators, steam at $105^{\circ} \mathrm{C}$. was applied to the interior of the uterus for one minute. The patient died on the third day after the operation, with the signs of septic peritonitis. At the post-mortem examination a perforation into the peritoneal cavity was found in the anterior wall of the uterus near the fundus. It is probable that in this case the uterus had contracted down on to the end of the tube, and that the latter had acted as a cautery and produced secondary sloughing of the uterine wall. Of the two other fatal cases recorded by Pincus, one occurred in private practice, and no details are forthcoming, and in the second a pyosalpinx appears to have ruptured during the operation. Such a result cannot occur if the rule that disease of the appendages forms an absolute bar to vaporization being undertaken is carefully observed.

Pincus has collected 833 cases of vaporization; of these, 749 were cured or benefited, and 3 died-a mortality of 37 per cent., or about the same as that attending the operation of curettage.

When properly carried out, atmocausis is certainly not more dangerous than any other form of intra-uterine manipulation. While the chances of the occurrence of stenosis or atresia of the cervix and that of obliteration of the uterine cavity are possibly greater than after curettage, yet it must not be forgotten that such accidents do occur even after the latter operation, and cases of this kind have been recorded by Fritsch, Wertheim, and others.

Of the seventy-two cases recorded by Steinbüchel, stenosis of the cervix occurred in two cases, and closure of the internal os in one case. All three cases were readily cured by dilatation, and the last patient subsequently became pregnant. Schlutius met with stenosis of the cervix once in an experience of fifty-seven cases. In this instance the zestocautery had been employed.

A case in which very marked atrophy of the uterus followed vaporization has been recorded by Baruch. The patient, a woman twenty-seven years of age, was delivered of a full-term child in December, 1895 . On the fifth day after delivery a rise of tempera- 
ture occurred, and she was confined to bed for three weeks. The periods, although she did not suckle, did not return until four and a half months after delivery, when they came on profusely, and lasted eight weeks. For this vaporization of the uterus was performed by a medical man. The bleeding at once ceased, and did not return. The periods failed to reappear, and the patient, who had previously been quite regular, began to complain of headaches, flushing, and palpitation of the heart. When seen in November, 1897 , the uterus was found to be hard, very small, retroverted, and completely fixed. A sound could not be passed, and the cervical canal was found to be obliterated. No details are known as to the temperature of the steam or the length of time for which it was applied.

By the application of steam at a high temperature for as short a time as possible, and by the use of a properly protected cannula, the risk of these mishaps can be reduced to a minimum.

The various conditions of the uterus for which atmocausis and zestocausis have been recommended as appropriate methods of treatment are at the present time very numerous, and this is not surprising when we remember that Pit'ha, one of its main adherents, considers that the steam can act as an antiseptic, disinfectant, deodorant, caustic, and local anæsthetic. No doubt further experience will show that the method is not suitable for some of the conditions for which it is at present employed, and yet other conditions will be found in which it will give good results.

The indications laid down by various writers at the present time are the following:

I. The main varieties of endometritis, including glandular, interstitial, gonorrhœal, senile, and endometritis with dysmenorrhœa.

2. Secondary post-partum hæmorrhage and subinvolution of the uterus.

3. Hæmorrhage from the uterus in cases of interstitial fibroid tumours.

4. Preclimacteric and climacteric hæmorrhages.

5. Hæmorrhage from the uterus in cases of hæmophilia.

6. Cases of puerperal sepsis in which the infection is still confined to the uterus.

7. Cases of putrid abortion, with septic intoxication.

8. In all cases as an alternative measure where total extirpation of the uterus is under consideration for severe hæmorrhage or discharge.

9. In cases of erosion or chronic inflammation of the cervix, and as a palliative measure in cases of carcinoma of the uterus. 
Io. To obliterate the uterine cavity after supravaginal amputation of the cervix.

II. To render sterile the interior of the uterus before the performance of hysterectomy.

12. To destroy the mucous membrane of the body of the uterus, so as to avoid the possibility of carcinoma developing in it.

13. To produce artificial sterility by the destruction of the functions of the endometrium or by obliteration of the uterine cavity.

In discussing these several indications it will be necessary to consider the results obtained by vaporization as compared with those obtained by other modes of treatment.

In cases of endometritis accompanied by severe hæmorrhage or discharge atmocausis may give relief when all other means have failed to do so. The two operations of curettage and vaporization have been so frequently combined in these cases that it is difficult to estimate their separate value. Cases where the mucous membrane of the uterus is definitely thickened are probably best treated by curettage, and Flatau's conclusions are sound-viz., that the curette answers best in glandular hypertrophic endometritis, and the atmocautery answers best in interstitial endometritis. Further observations, with detailed descriptions of the condition of the mucous membrane, are necessary before we can say exactly what kind of endometritis is best suited for one or other of these modes of treatment.

Of eight cases that I have treated by curettage and vaporization, and in which more than six months have elapsed since the performance of the operation, three were patients suffering from severe menorrhagia not due to the menopause.

The details of these cases are shortly as follows :

CASE I.--L. M., aged thirty-seven years, single ; admitted to hospital complaining of excessive irregular hæmorrhage of six months' duration. The periods commenced at the age of eleven years, and were regular and normal in quantity until an attack of congestion of the lungs six months before admission. Patient's general health good. Medicinal treatment had failed to arrest the bleeding. Uterus found to be normal in position and not enlarged. Under an anæsthetic nothing abnormal detected on examination with the finger. Uterus curetted and steamed for fifteen seconds at $I 10^{\circ}$ to $\mathrm{I} I 2^{\circ} \mathrm{C}$. * Uninterrupted convalescence. Examination of scrapings showed slight increase in amount of gland tissue. When last heard of, three months after operation, patient was well, menstruating regularly and not excessively.

CASE 2.-B. C., thirty years of age, single. Patient had been curetted

* In all instances the temperature, when quoted, refers to that of the steam in the boiler. 


\section{Blacker: Vaporization of the Uterus}

for hæmorrhage from uterus three years and one year previously in another hospital. On second occasion chorionic villi found in scrapings. Six weeks before admission patient commenced to bleed again, and passed large quantities of blood and clots. She had not missed a period, and before the two previous operations she had been quite regular. Uterus small, appendages normal, endometrium smooth; curetted and steamed for thirty seconds at $110^{\circ}$ to $115^{\circ} \mathrm{C}$.

On occasion of first operation slight thickening of the endometrium was found. Microscopic examination of the scrapings removed on the present occasion showed slight glandular endometritis. Two months after operation the patient was well ; since then she has been lost sight of.

CASE 3.-S. M., thirty-eight years of age. Has had three children and one miscarriage; youngest child twelve years old. For several years past the patient had suffered excessive loss at her periods, which lasted seven to ten days, recurring every three to four weeks, and during the first four or five days of which she had to keep to her bed. The amount lost was gradually getting greater, and medical treatment had quite failed to relieve it. General health poor; uterus a little enlarged; sound passed in 3 inches; no evidence of the presence of any fibroid tumour ; appendages healthy. Under anæsthesia uterus explored; interior appeared normal, curetted and steamed at $105^{\circ} \mathrm{C}$. for thirty seconds. Microscopic examination of the scrapings showed apparently healthy mucous membrane. Uninterrupted recovery. No improvement has followed the operation; the patient is regular and still loses excessively. A thick leucorrhoeal discharge from which she suffered before the operation is now replaced by a quantity of thin serous matter coming away between the periods.

In two of the three cases the hæmorrhage was due to endometritis, while in the third patient no changes could be detected in the endometrium. The two cases of endometritis were definitely benefited by the operation, the remaining case was not.

Steinbüchel treated twenty cases of endometritis with copious purulent discharge by atmocausis. Of these, fifteen were cured ; in one case the amount of discharge was lessened, and in two cases the treatment failed to give any relief. Of seven cases of chronic metritis and endometritis with purulent discharge treated by Schäffer, three were cured, three improved, and one showed no improvement. This case was treated by zestocausis for a quarter of a minute at I $5^{\circ} \mathrm{C}$., a quarter of a minute at I I $2^{\circ} \mathrm{C}$, and for ten seconds at $109^{\circ} \mathrm{C}$. A slight attack of pelvic cellulitis follcwed, the only occasion out of twenty-seven cases treated by this operator in which any aftercomplication occurred.

When the profuse discharge of a case of senile endometritis does not yield to ordinary methods of treatment vaporization may be tried, and such cases are suitable ones in which to bring about total obliteration of the uterine cavity. The supposed bactericidal action of the steam has been adduced as a reason for employing it in cases of gonorrhœal endometritis. The experiments we have detailed as to the actual temperature of the steam in utero renders the question of its bactericidal action very doubtful. 
Fenomenow came to the conclusion, from a bacteriological examination of the contents of the uterus after vaporization, that the steam acted as a bactericide. He appears, however, to have assumed that the uterine cavity previous to the steaming contained organisms. This, of course, is not necessarily the case. To overcome this objection, Flatau introduced a culture of the Bacillus pyocyaneus into the interior of some uteri. He then steamed the uteri with steam at a temperature of $105^{\circ}$ to $110^{\circ} \mathrm{C}$. in the boiler, for one, two, or three minutes. At the conclusion of the experiments a bacteriological examination of the uterine contents showed the bacilli in all the cases to be still alive, and to have been unaffected by the steam.

A possible explanation of the result obtained in gonorrhœal cases is that it is not due to the action of the steam upon the organisms themselves, but to its effects upon the blood, mucus, and tissues in which they are growing.

Schäffer records seven cases of gonorrhœal endometritis and metritis with purulent discharge. He treated five of these with atmocausis: in three cases the discharge was cured, in one case it was lessened, and in one case it continued unaltered. Two cases of gonorrhœal discharge treated with zestocausis were both benefited, while a case of gonorrhœal hæmorrhagic endometritis was cured by atmocausis.

If the doubts thrown upon the bactericidal action of the method prove to be well founded, the plan of attempting to sterilize the uterine cavity by vaporization before hysterectorny must be given up.

Pincus and others have used the zestocautery in cases of endometritis with dysmenorrhoa with encouraging results. It is difficult to assign their true value to such successes. The good results may have been due, not to the vaporization, but to the preliminary dilatation of the cervix. It is more than questionable whether in any large number of these cases such energetic treatment is required, and I do not think that there is sufficient evidence of its utility to justify the continued use of the zestocautery in this or any other condition.

Cases of subinvolution of the uterus and secondary post-partum hæmorrhage do not as a rule require vaporization unless all other methods of treatment have failed. The danjer of causing total obliteration of the cavity of the uterus in a ycung woman, a result especially likely to occur during the puerperium, renders the warning a good one that vaporization should always be practised with great caution upon a patient far removed from the menopause.

The danger of the application of steam to the uterus in the case 


\section{Blacker : Vaporization of the Uterus}

of submucous fibro-myomata is much the same as that likely to follow the use of the curette-viz., the risk of causing sloughing of the tumour.

A case operated upon by Flatau illustrates this danger. The patient, thirty-eight years of age, had a myoma the size of a goose's egg in the left uterine wall. Curettage on two occasions and treatment with ergot had given temporary relief only to the hæmorrhage. Atmocausis at a temperature of $108^{\circ}$ to $I \mathrm{I} 2^{\circ} \mathrm{C}$. was carried out for two minutes. The patient left the hospital well, but returned after an interval of two weeks complaining of pain in the abdomen, with high fever, a rapid pulse, and a profuse purulent discharge. The myoma was found to be sloughing, and had to be removed by enucleation.

In the case, however, of small interstitial fibroid tumours causing such severe hæmorrhage that extirpation of the uterus is contemplated, vaporization is likely to be of value. The cavity of the uterus must not be too large, and should be regular in shape if the best results are to be attained.

Pincus has collected twenty-six cases of fibro-myomata of the uterus treated by atmocausis for severe hæmorrhages. In twentythree cases the result was good, in two cases only temporary improvement followed, and in one case the treatment entirely failed. Of the twenty-three successes, thirteen had been watched for periods varying from six months to four years, and the good result had been so far permanent. In four of the cases atmocausis was practised twice; in one of these cases failure occurred. Nine of the patients had been previously curetted, four of them twice, and two three times. These two cases had also had the uterine arteries tied without effect. In all these nine cases vaporization arrested the bleeding, and the good results lasted during the time they were under observation, from six months to four years.

The most certain indications for the practice of atmocausis are afforded by cases of preclimacteric and climacteric hæmorrhages. The results are often surprisingly good, and the dangers practically nil. The application of steam at $110^{\circ} \mathrm{C}$. for one minute is usually sufficient to check the hæmorrhage completely, or, at any rate, for some considerable time, and is often followed by the menopause, with atrophy of the uterus, and at times obliteration of its cavity. If the latter result be desired, it is best to repeat the vaporization after an interval of three or four weeks has elapsed. In these cases it is of great importance to protect the cervix, so that obliteration of the cervical canal may not precede that of the body, and lead to the 
formation of a hæmatometra. Fuchs has recorded the results obtained in twenty-two cases of preclimacteric and climacteric hremorrhages. In six the menopause followed at once; in seven, after an interval of no loss lasting for a variable length of time, the periods returned, but in greatly lessened quantity; while in nine the periods returned after no interval, but in a less amount than before. Seven of the cases had been previously curetted with no result. In twelve cases treated by Lachmann, in three the periods ceased at once, in two they continued regularly, in three irregular hæmorrhage occurred, in one case to an excessive degree, while of the remaining four cases two were lost sight of, and in two the result was said to be good.

Of my own eight cases, five were examples of preclimacteric or climacteric hæmorrhage. In two of the cases interstitial fibromyomata were present. Of the five cases, in four the hæmorrhage ceased after the operation, and has not returned since, two years, fourteen months, nine months, and six months having elapsed. In one case the result has been only temporary improvement, although the patient thinks that she is losing less now at her periods, fourteen months after the operation, than she did after a previous operation of curettage alone.

The details of these cases are as follows:

CASE I.-C. S., forty-one years of age, has had one child and two miscarriages, the last one five years previously. The periods began at seventeen years of age, and had been regular and normal in amount until the last nine months. During this time they had recurred every fourteen days, and lasted six to seven days. Numerous large clots were passed. Patient's general health was deteriorating, and she suffered from anæmia, neuralgia, insomnia, and loss of flesh. During the last few months flushings had occurred from time to time. Uterus a little bulky, interior smooth, appendages normal. Dilated, curetted, and steamed for thirty seconds at I I $5^{\circ}$ to $116^{\circ} \mathrm{C}$. Good recovery; nine months later the patient was very well. No return of hæmorrhage at all since operation, and no sign of periods. General health much improved. Microscopic examination showed no definite changes in mucous membrane.

CASE 2.-H. R., forty-four years old. Had had six children and one miscarriage, last child seven years previously. Since the birth of the last child the periods had been excessive, lasting at times as long as fourteen days and recurring after a clear interval of only a few days. Periods began at fifteen years of age, and were regular until the patient was thirty-seven years old. Two years before admission the patient had had severe hæmorrhage, amounting to a flooding on one occasion and lasting for three weeks. The uterus was curetted with slight benefit, the periods recurring after this every three weeks and lasting from seven to ten days. On entering the hospital, she was profoundly anæmic and bleeding profusely. The uterus was retroverted and a little enlarged, appendages healthy. Uterus explored with finger, curetted and steamed for forty-five seconds at $110^{\circ}$ to I I $2^{\circ} \mathrm{C}$. Patient made uninterrupted recovery. Ten days after leaving hospital the patient had a period, losing a fair amount. Since then, now six months 


\section{Blacker: Vaporization of the Uterus}

ago, she has had a trifling show on two occasions, but no further bleeding. Her health at the present time is good.

Case 3.-M. J., forty-five years old, three children, no miscarriages. For last few years the patient has been losing very excessively at her periods, which had recurred every ten to fourteen days and lasted nearly four weeks. Curetted ten months ago with temporary benefit for about three periods, then excessive loss recommenced. Patient, when seen, was profoundly anæmic and very feeble. Uterus a little enlarged and apparently contained an interstitial fibroid. Interior normal, no submucous fibroid present ; curetted and steamed for thirty-five seconds at $105^{\circ} \mathrm{C}$. Microscopic examination of scrapings showed slight glandular endometritis.

Improvement lasted about nine months; since then the loss at the periods has again begun to increase, and the patient is now, fourteen months after the operation, losing almost as much as before the steaming. I am inclined to attribute the failure in this case to the fact that probably the temperature of the steam-IO $5^{\circ}$ - was not high enough, and the length of time during which it was applied-thirty-five seconds-was not long enough for so severe a case. Possibly a second application four weeks later might have given a more permanent result.

CASE 4.-E. B., agyed forty-eight years. Had one child twenty-seven years ago. For the last five years the patient has suffered severe pain in the right side and excessive loss at her periods. For the last two years the hæmorrhage has been excessive, lasting for four weeks at a time and recurring after an interval of two weeks. For six months past the patient has had severe bleeding on the slightest exertion. When first seen at her home, the patient was so anæmic and weak from loss of blood that it was a question whether it would be safe to remove her to the hospital.

A week after admission thrombosis of the left brachial vein and of the left external jugular vein occurred. The bleeding was checked by hot douches and ergotine, and operation was postponed until five weeks after admission. The hæmorrhage continued, but much less in amount, for four weeks. After dilatation of the cervix the uterus, which was about the size of the organ at three and a half months' gestation and contained some interstitial fibroids, was curetted and steamed for sixteen seconds at $110^{\circ}$ to $I 15^{\circ} \mathrm{C}$. Uninterrupted recovery. The scrapings showed slight interstitial endometritis. Since the operation, now fourteen months ago, the patient has not had any return of the bleeding, and at the present time is in robust health.

CASE 5.-M. C., forty-nine years old, widow. Has had fourteen children and no miscarriages. For last two years periods excessive in amount and recurring every three weeks. For the last six weeks the patient has been losing continuously and to a considerable extent. Uterus bulky, outline regular. Mucous membrane smooth. Dilated, curetted, and steamed for one minute at $100^{\circ}$ to $105^{\circ} \mathrm{C}$. Little hæmorrhage continued for ten days after operation, and then ceased. Patient quite well at the present time, two years after the operation, and has had no return of the hæmorrhage.

It is a fortunate occurrence that cases of hæmophilia are not frequently met with in women. The application of steam to the uterus in four cases of excessive menorrhagia in bleeders has been carried out by Pincus, Stoeckel, Gummert, and V. Guérard, with good results in all four instances.

The details of Gummert's case are as follows :

The patient, a bleeder, was fifteen years old. She had menstruated twice, on the last occasion for three weeks. The hæmorrhage was suffi- 


\section{Journal of Obstetrics and Gynæcology}

cient to threaten her life. Pulse on admission 140 , temperature $38^{\circ} \mathrm{C}$. Atmocausis at $\mathrm{I}_{10} \mathrm{O}^{\circ} \mathrm{C}$. was carried out for fifteen seconds, without anæsthesia. Marked contraction of the uterus occurred, and the bleeding at once ceased. The next three periods recurred after intervals of six, four, and eight weeks, and were not unduly excessive.

V. Guérard's patient was a single girl of twenty-one years of age. She was a bleeder, and her mother, also a bleeder, had died of hæmorrhage at a period. A sister had died of acute pernicious anæmia at seventeen years of age. The girl herself, when she came under observation, was suffering from very excessive loss at her periods, which had not yielded to medical treatment.

Curettage and vaporization for twenty seconds at $105^{\circ} \mathrm{C}$. were practised. Very profuse hæmorrhage followed the curettage, which the atmocausis at once arrested. It recurred after fourteen days, and lasted a fortnight. With a view to obliterating the uterine cavity, atmocausis without curettage was practised a second time at $115^{\circ} \mathrm{C}$. for thirty seconds. Eight days later the patient was able to travel. She was to write if any further hæmorrhage occurred, but no news had been received of her when the case was recorded.

Pincus had under his care a woman twenty-three years old, a bleeder, who had been bleeding from the uterus for three and a half weeks incessantly. Plugs, douches, and medicines had failed to arrest the hæmorrhage. Severe oozing continued in spite of vaginal plugging, and finally caused fainting. Atmocausis was practised for six seconds at I $5^{\circ} \mathrm{C}$. without anæsthesia. The hæmorrhage ceased, and did not recur for three months. Since then the patient has menstruated regularly every month for three or four days without pain and not excessively.

Stoeckel's case was that of a young girl, fourteen years of age, suffering from excessive uterine hæmorrhage, which medicine and complete rest had failed to arrest. She was admitted to hospital, after six weeks' hæmorrhage, almost moribund. She was extremely anæmic, very feeble, unable to walk or stand; the mucous membranes were quite bloodless, and the pulse small, thready, and 140 per minute. There was a well-marked subcutaneous hæmorrhage in the right hypogastric region, and she gave a history that she had been subject to such hæmorrhages for the past three years. After the extraction of a tooth she had nearly bled to death. There was no family history of hæmophilia. Atmocausis at $115^{\circ} \mathrm{C}$. was practised for two and a half minutes. The hæmorrhage ceased at once and did not return. She made an uninterrupted recovery, and was able to leave the hospital eight weeks afterwards. At this time the sound passed in for a distance of 2 centimetres only. Four months later the patient had had no return of the bleeding. Although the diagnosis of hæmophilia in the case was not certain, the vaporization undoubtedly saved the life of the patient, who was not in a condition to stand any more severe treatment. It is probable that the cavity of the body of the uterus became obliterated. This is the youngest patient at the present time upon whom the operation of atmocausis has been performed.

The propriety of the local treatment of cases of puerperal sepsis is a matter that cannot be said to have been finally settled. In the report of the committee appointed by the American Gynæcological Society to consider the value of antistreptococcic serum in cases of puerperal fever, one of the conclusions arrived at is as follows: "We unhesitatingly condemn curettage and total hysterectomy in streptococcus endometritis after full-term delivery, and attribute a large 
part of the excessive mortality in the cases recorded in the literature of the subject to the former operation.'

The results hitherto obtained by energetic local treatment of such cases are not sufficiently encouraging to lead us to hope much from vaporization. The method has not been tried in a sufficiently large number of cases to warrant our coming to any definite conclusion upon the subject. It must be remembered that the mortality of cases of endometritis due to the presence of the streptococcus when left alone is probably not more than 5 per cent.

It was originally suggested by Pincus that in cases of incomplete abortion vaporization should be employed to sterilize the contents of the uterus before their removal. Experience soon proved the futility of any such procedure, and Pincus has apparently now modified his views, and recommends vaporization after removal of the decomposing material, not before. This is a class of case in which the application of steam is not likely to do any harm, but in which it is doubtful if it is likely to do much good.

When we consider the superficial character of the results observed in the mucous membrane of the uterus after steaming it is very unlikely that vaporization could have any great effect upon masses of retained placenta, often of considerable thickness. In a case recorded by Stoeckel atmocausis at $105^{\circ} \mathrm{C}$. for forty-five seconds was performed before removal of the uterus. On laying the uterus open, a small mucous polypus was found attached at one tubal angle. The polypus was practically unaffected by the steam. Such a result renders the probability of any marked effect of vaporization upon a retained portion of placenta a very doubtful matter.

If the condition be one of septic intoxication, the removal of the putrid contents of the uterus is usually followed by a rapid fall of the temperature and the recovery of the patient. The use of the finger in these cases gives such good results that no further treatment is, as a rule, required.

Cases are recorded from time to time in which total extirpation of the uterus has been performed on account of severe hæmorrhage in patients in whom there was no suspicion of hæmophilia.

The cause of the bleeding is very often the onset of the menopause, the presence of small interstitial fibroid tumours in the uterus, or possibly sclerotic changes in the arteries of the uterine wall. In some cases no adequate cause of the hæmorrhage is manifest, and attempts have been made to explain them by supposing them to be examples of 'relative insufficiency of the uterine muscle' (Theilhaber) or 'chronic atony of the uterus' (Lomer). In all such 
instances where total extirpation of the uterus is under consideration a preliminary trial of vaporization may well be made, and, if necessary, repeated. If this were the only good result that had been obtained by the use of atmocausis-viz., the avoidance of total extirpation of the uterus in any one case-that alone would be sufficient to justify our retaining the operation as an approved surgical measure.

The following case recorded by Fisher illustrates the value of atmocausis under these conditions :

A patient, fifty-three years of age, suffering from very marked menorrhagia. Curettage had been practised on several occasions in two hospitals without result. Malignant disease was excluded. The uterus was large and soft, the sound passing 6 inches. The patient was very nervous and extremely anæmic. Atmocausis for fifteen seconds at i I $5^{\circ} \mathrm{C}$. was carried out. The bleeding ceased, and had not recurred five months afterwards. Marked involution of the uterus followed the operation. Four weeks after the operation the sound passed 4 inches, three months afterwards $3 \%$ inches, and four and a half months afterwards 3 inches. The uterine tissue was now hard, and no longer tender. It was intended to practise total extirpation had vaporization failed.

Wehmer records the case of a patient thirty-two years of age with very profuse loss at the periods lasting twelve to fourteen days. Curettage and other means of treatment had failed to relieve the bleeding. The question of removal of the ovaries or extirpation of the uterus was considered, but it was decided to practise vaporization first. This was performed for thirty seconds at $105^{\circ} \mathrm{C}$. A good result followed, and the patient was well and her periods regular nine months afterwards.

The zestocautery has been suggested as a means of treating cases of erosion, chronic inflammation, and carcinoma of the cervix. There are no good reasons for preferring the zestocautery to any other form of cautery in these cases, and it does not appear to present any advantages over the electric or Paquelin's cautery.

With a view to diminishing the frequency of the occurrence of carcinoma of the uterus, Dührssen has proposed that in women predisposed to cancer and of an age at which it might be expected to occur, the cervix uteri should be amputated and the mucous membrane of the body of the uterus destroyed by atmocausis. No doubt, if it were possible to practise such preventive operations upon any large proportion of the total number of women, the number of cases of cancer could be lessened ; but the suggestion is so purely visional that it is beyond the range of practical surgery.

Amongst the objections urged against the operation of supravaginal amputation of the cervix are the possibility of the patient 
becoming pregnant after the operation and the likelihood of the scar contracting and producing obstructive dysmenorrhœa. Both these dangers could be eliminated by producing obliteration of the uterine cavity after removal of the cervix, and I would suggest that this should be done in all cases of supravaginal amputation of the cervix for carcinoma in women before the menopause, by means of vaporization of the uterus.

In view of the very excellent results obtained by Byrne of New York with his operation of electro-hysterectomy, in which he removes the cervix and the whole of the mucous membrane of the body of the uterus with the electric cautery, it is evident that supravaginal amputation of the cervix is by no means the obsolete operation that many of its opponents hold it to be, and two of the chief objections to its employment could be obviated by combining with it total obliteration of the cavity of the uterus.

In forty out of sixty-three cases of cancer of the portio-vaginalis operated upon by Byrne (twenty-three having been lost sight of), periods of exemption from recurrence were obtained ranging from two to twenty-two years. In fifty out of eighty-one cases of carcinoma of the cervix (thirty-one not traced) ten were free from recurrence at the end of two years, eleven over three years, six over four years, eight over five years, six over seven years, two over eleven years, one over thirteen years, and one over seventeen years.

The last indication for the employment of vaporization is the production of artificial sterility by destruction of the functions of the endometrium, or obliteration of the cavity of the uterus.

Pincus has recorded two such cases:

The first was a patient aged twenty-six years, with phthisis, who had had two children. As the result of the last confinement and pregnancy the disease in the lungs had made marked progress. In view of this fact, and to avoid the danger of any further pregnancies, it was decided to produce artificial sterility. This was effected by the application of steam to the interior of the uterus on two occasions, for forty and fifty seconds, at a temperature of $110^{\circ} \mathrm{C}$. The patient made a good recovery and the periods entirely ceased, the cavity of the uterus becoming obliterated.

The second case was that of a patient suffering from Bright's disease, who had had four children. The uterus was steamed for one minute at $115^{\circ} \mathrm{C}$., and three weeks later for the same length of time with steam at I $2^{\circ} \mathrm{C}$. Obliteration of the upper part of the uterine cavity and total cessation of the periods followed.

From this consideration of the advantages and disadvantages of atmocausis and zestocausis, and of the results obtained by their use, the following conclusions may, I think, be drawn:

When carried out as a surgical operation, and with the precau- 
tion necessary for a surgical operation, atmocausis is a procedure practically without danger.

This mode of treatment is undoubtedly of value in certain cases; but while it may supplement the use of the curette, it can never replace the latter instrument.

The main conditions for the treatment of which it is useful are :

I. Hæmorrhage from the uterus in cases of hæmophilia.

2. Cases of severe preclimacteric and climacteric hærnorrhage.

3. As an alternative mode of treatment where extirpation of the uterus is considered necessary for severe hæmorrhage.

4. To produce total obliteration of the remaining portion of the uterine cavity in cases of supravaginal amputation of the cervix.

5. To produce artificial sterility where such treatment is indicated.

6. In certain other conditions, such as hæmorrhagic endometritis, or endometritis with interstitial fibroids where curettage has failed.

7. The zestocautery presents no advantages over any other kind of cautery, such as the electric or Paquelin's cautery, and its use is not to be recommended.

It is unfortunate that some of the writers upon vaporization of the uterus have advocated this mode of treatment with so little discrimination. Attempts to show that it is the best method of treating a large number of very different conditions cannot but lead to the discredit of an operation which, within certain well-defined limits, should prove a measure of permanent value.

\section{BIBLIOGRAPHY.}

BARUCH, FeLIX : Centralbl.f. Gynäk., I898, No. 5, p. II3.

BASSECHES : Sammelbericht Wien. Med. Blätter, 1898, Nos. 47-50.

BeutTNer, OsCaR : Centralbl.f. Gynök., 1899, No. 33, p. 993 ; Wien. Klinik. xxvi. Jahrg., Heft 5.

BREnNeCKe: Monatschr. f. Geburtsh. u. Gynï̌k., Bd. X., 1899, Heft 3, p. 404.

Brothers : Am. J. Obst., N.Y., I899, October, p. 498.

CzEMPin : Centralbl.f. Gynäk., 1900, No. 1, p. 29 ; 1900, No. 6, p. 185.

Donati: Bolletino Med. Trentino, 1900, No. 7 ; 1901 , Nos. I and 2.

DüHRSSEN : Centralbl. f. Gynäk., 1900, No. 3, p. $90 ;$ Verhundl. der Deutsch. Gesellsch. f. Chirurgie, Berlin, 1898, p. 495 ; Centralbl. f. Gynäk., 1899, No. I I, p. 292 ; Berl. Klin. Wchnschr., 1898, No. 36, p. 795 ; Centralbl. f. Gynäk., 1900, No. 5, p. 146 ; Deutsche Med. Wchnschr., 1899, No. 4, p. 60.

FALK : Centralbl. f. Gynäk., 1901, No. 33, p. 955 ; Monatschr.f. Geburlsh.u. Gynäk., January, 1902.

FENOMENOW : Centralbl. f. Gynäk., i 898, No. 23, p. 606.

FlataU : Monatschr. f. Geburtsh. u. Gynäk., Bd. X., I899, p. 337 ; Centralbl. f. Gynäk., 1900, No. 3, p. 90.

FkANK : Centralbl.f. Gynäk, 1900, No. 39, p. 1017. 


\section{Blacker: Vaporization of the Uterus}

Fraenkel: Centralbl.f. Gynïk., igor, No. 36, p. 1024.

FREUND : Brit. Gyncec. J., Lond., vol. lxiv., Summary, p. I84.

FucHs : Mïnchen. Med. Wchnschr., 1901, No. 22, p. 869.

GERICH, O. : Centralbl. f. Gynäk., 1899, No. 19, p. 557.

GUÉRARD, V. : Centralbl. f. Gynäk., 1899, No. 35, p. $108 \mathrm{I}$.

GUMMERT: Monatschr. f. Geburtsh. u. Gynäk., Bd. X., 1899, p. 404.

JaWORSKI : Wien. Med. Presse, 1895, No. 3, p. 84.

KAH. : Centralbl.f. Gynäk., 1896, No. 49, p. 1233; 1898, No. 23, p. 618.

Koslenko: Centralbl.f. Gynäk., ı901, No. 17, p. 442.

LACHMANN: Mïnchen. Med. Wchnschr., 1901, May, p. 875.

MACAN : Brit. M.J., Lond., I900, April 14.

NEugebaukr: Centralbl. f. Gynäk., 1895, No. 3, p. 74.

PANeck1 : Therap. Monatsh., Berlin, 1896, January, p. 20.

PINCUS, LUDWIG : Centralbl. f. Gynïk., I895, No. I1, p. 284 ; 1899, No. 4, p. II 3 ; 1900 , No. 25 , p. $641 ; 1897$, No. 7 , p. $190 ; 1898$, No. 10, p. $256 ; 1898$, No. 22 , p. 582 ; 1898, No. 38, p. 1019; 1899, No. 13, p. 352 ; 1899, No. 33, p. 1010; 1899, No. 40, p. I221 ; Sammt. Klin. Vorträge, N. F., No. 238 (Gynäkologie, No. 86), March, 1899 ; Nos. 261 and 262 (Gynäkologie, No. 94), December, 1899; Centralbl. $f$ Gynäk., I90I, No. 34, p. 964 ; Monatschr. f. Geburtsh. u. Gynïk., Bd. X., 1899, March, p. 515 ; Therap. Monatsh., Berlin, 1899, August, p. 447 ; Centralbl. $f$. Gynäk., 1902, No. 8, p. 203.

Piт'HA: Centralbl. f. Gynïk., 1897, No. 22, p. $652 ; 1897$, No. 27, p. 881 ; 1899, No. 33, p. rol I.

Prochownick : Centralbl.f. Gynitk., I899, No. 23, p. 705.

ScHICK : Centralbl.f. Gynäk., I897, No. 23, p. 695.

SCHICHOLD : Deutsche Med. Wchnschr. Therap. Beilage, I899, No. 3, p. 16; Centralbl. f. Gyniik., I899, No. 47, p. 1430.

Schlutius : Centralbl. $f$. Gynitk., 1899, No. 40, p. 1225; Therap. Wchnschr., 1899, No. 12, December.

Simpson : Scottish Med. Surg. J., I900, June, p. 499.

SneguirefF: Deutsche Med. Wchnschr., 1894, No. 38, p. 747; 'Comptes Rend. de XII. Congress Int. de Médecine,' Moscow, vol. vi., Section XIII., p. 263; Samml. Klin. Vortrïge, I 895, Heft 82.

STAPLER : Centralbl.f. Gynäk., I899, No. 33, p. 1000.

Steineüchrl: Centralbl. f. Gynak, 1899, No. 40, p. 1222 ; Monatschr. $f$. Geburtsh. u. Gyniik., Bd. XI., p. 546.

Stoeckel. Brit. Gynac. J., vol. lxiii., Summary, p. 129; Therap. Monatsh., 1900, No. 12, p. 644 .

UTERMANN : 'Ueber Vaporisation des Uterus,' Dissertation, Kiel, I900.

VAN DE VFLDE: Centralbl.f. Gynïk., 1898, No. 52, p. 1409.

WeISS : Centralbl. f. Gynäk., 1898, No. 24, p. 636.

Zengerlé: Die Praxis, 1896, No. 15 ; Centralbl.f. Gynäk., 1897, No. 8, p. 218. 